\title{
Corrosion Performance of Stainless Steel and Nickel Alloys in Aqueous Sodium Hydroxide as Revealed from Cyclic Voltammetry and Potentiodynamic Anodic Polarization
}

\author{
M. ABDALLAH ${ }^{1,2, *}$, M. M. SALEM ${ }^{3}$, I. A. ZAAFARANY ${ }^{2}$, A. FAWZY' ${ }^{1,4}$ and A. A. ABDEL FATTAH ${ }^{1}$ \\ ${ }^{1}$ Chemistry Department, Faculty of Science, Benha University, Benha, Egypt. \\ ${ }^{2}$ Chemistry Department, Faculty of Applied Sciences, Umm Al-Qura University, Makkah, Saudi Arabia. \\ ${ }^{3}$ Chemistry Department, Faculty of Sciences in Zulfi, Majmaah University, Saudi Arabia. \\ ${ }^{4}$ Chemistry Department, Faculty of science instead of Faculty of Sciences, Assiut University, Assiut, Egypt. \\ ${ }^{*}$ Corresponding author E-mail: metwally555@yahoo.com
}

http://dx.doi.org/10.13005/ojc/330621

(Received: November 08, 2017; Accepted: November 25, 2017)

\begin{abstract}
The electrochemical behavior of nickel, Inconel 600, Incoloy 800 and 316 stainless steel electrodes in different concentration of $\mathrm{NaOH}$ solution was investigated using the cyclic voltammetry technique (CV). All the curves in the anodic branch of the CV are characterized by anodic dissolution peak $(A)$, passive region $(B)$, anodic dissolution peak $(C)$ before oxygen evolution. In the case of the cathodic branch of CV there is one reduction peak (D) in case of Ni electrode but there are two reduction peaks ( $D$ and $E$ ) in case of the three alloys used. All these peaks are explicated. The effect of chloride ion as a pitting agent on the cyclic voltammetry and the potentiodynamic anodic polarization of $\mathrm{Ni}$, Inconel 600, Incoloy 800 and 316 SS electrodes in $\mathrm{NaOH}$ solution was investigated. As the concentrations of the chloride ions increase the change of the amount of the anodic charge $\Delta \mathrm{q}_{\mathrm{a}}$ increases and the values of the pitting corrosion potential are shifted to the more negative direction indicating the breakdown of passivity and the imitation of the pitting corrosion. At one and the same $\mathrm{Cl}^{-}$ion concentration, the resistance to the pitting attack decreases in the following order: 316 SS > Inconel $600>$ Incoloy $800>316$ SS. This order depends on the chemical composition of these alloys.
\end{abstract}

Keywords: Nickel, Inconel 600, Incoloy 800, 316 SS, Cyclic voltammetry, Pitting corrosion.

\section{INTRODUCTION}

Nickel alloys and stainless steels (SS) are used extensively in several industrial applications where heat resistance and/or corrosion resistance is required. Nickel is one of the materials most resistant to a variety of caustic solutions (sodium hydroxide), as well as to molten caustic. Various nickel alloys and stainless steel also have been widely used in sodium hydroxide production and in many other industries using caustic applications ${ }^{1}$.

The cyclic voltammetry technique is useful for identifying the steps involved in the overall reactions resulting in the formation of various films on the metallic surfaces ${ }^{2}$. It is particularly useful for distinguishing between products resulting from chemical, electrochemical reactions. Its main 
limitation is that, it is only useful for examining very thin films formed in a relatively short time.

The characteristic and theory of pitting corrosion has been discussed in details by Kolotyrkin ${ }^{3}$ who stated that, the pitting corrosion of a certain metal or alloy occurs within a definite potential range lying in the passive region. The formation and development of this type of attack on the metal surface can occur only in solutions containing the aggressive $\mathrm{Cl}^{-}, \mathrm{Br}^{-}$and $\mathrm{I}^{-}$ions ${ }^{4-12}$. The critical potential at which pitting initiates is reported by several authors and found to depend on a number of factors including the type and concentration of attacking anion, type of metal used and relative concentration of other anions ${ }^{13-14}$.

In the previous work ${ }^{15}$ the corrosion behavior of nickel, nickel alloys and stainless steel (SS) in various concentrations of $\mathrm{HNO}_{3}$ solutions using the cyclic voltammetry technique was studied. Also the pitting corrosion of these samples in chloride containing solutions and its inhibition by some inorganic compounds using potentiodynamic anodic polarization was also studied ${ }^{16}$. To complement this work, the cyclic voltammetry of $\mathrm{Ni}$, Inconel 600, Incoloy 800 and 316 SS electrodes were traced in $\mathrm{NaOH}$ solution as a function of $\mathrm{NaOH}$ concentration. Also, the effect of chloride ion as a pitting corrosion agent on the cyclic voltammetry and the potentiodynamic anodic polarization of $\mathrm{Ni}$, Inconel 600, Incoloy 800 and 316 SS electrodes in $\mathrm{NaOH}$ solution was further examined.

\section{EXPERIMENTAL}

The electrodes used in this study are nickel Inconel 600 , Incoloy 800 and 316 SS. The chemical structures of these electrodes are given in Table 1. A cylindrical rod embedded in Araldite with an exposed surface area to the corrosive medium of $1.70 \mathrm{~cm}^{2}$ for $\mathrm{Ni}, 1.57 \mathrm{~cm}^{2}$ for the Inconel $600,1.48$ $\mathrm{cm}^{2}$ for the Incoloy 800 and $1.44 \mathrm{~cm}^{2}$ for the $316 \mathrm{SS}$ was used. The electrolytic cell, electrode samples and surface treatment of the electrodes are the same as those described in previous work ${ }^{15,16}$.

For the cyclic voltammetry and the potentiodynamic anodic polarization techniques were carried out using a Wenking potentioscan, Type POS-73. The current density-potential curves were recorded on X-Y recorder, Type PL-3. Before carrying out any experiment, the working electrode was precathodized (for $20 \mathrm{~min}$.) at a potential of $-1.5 \mathrm{~V}$ in order to reduce the pre-immersion oxide film formed at the surface of the electrode.

Table.1: The chemical composition of the alloys used

\begin{tabular}{lcccccccccc}
\hline Alloys & Ni\% & Fe\% & Cr\% & Cu\% & Si\% & P\% & S\% & Mn\% & C\% & Others $\%$ \\
\hline Nickel & 100 & - & - & - & - & - & - & - & - & - \\
Incone 100 & 73.42 & 9.33 & 16.10 & 0.03 & 0.118 & 0.007 & 0.006 & 0.38 & 0.04 & Al 0.28, Ti 0.24, \\
& & & & & & & & & & Co 0.049 \\
Incoloy 800 & 33.49 & 44.95 & 19.32 & 0.27 & 0.32 & - & 0.007 & 0.81 & 0.063 & Al 0.39, Ti 0.38 \\
316 SS & 13.12 & 65.80 & 16.50 & - & 0.50 & 0.03 & 0.002 & 1.63 & 0.028 & Mo 2.35 \\
\hline
\end{tabular}

\section{RESULTS AND DISCUSSION}

\section{Effect of $\mathrm{NaOH}$ concentration}

The curves of Figs. 1-4 show the effect of various concentrations of $\mathrm{NaOH}$ solutions on the cyclic voltammetry $(\mathrm{CV})$ characteristics of $\mathrm{Ni}$, Inconel 600 , Incoloy 800 and 316 SS, respectively, upon the polarization range between $-1 \mathrm{~V}$ to $+1 \mathrm{~V}$ at a scanning rate of $25 \mathrm{mV} \mathrm{sec}{ }^{-1}$ versus the saturated calomel electrode (SCE).
Inspection of the curves of Figs. (1-4) reveals that there is anodic dissolution peak (peak A). As the concentration of $\mathrm{NaOH}$ increases, the dissolution current density for peak $(A)$ is increased due to the increase of corrosion rate with increasing the alkali concentration. It is clear from the curves of Figs. (1 and 2) for nickel and Inconel 600 (higher nickel content), that peak (A) appears at nearly the same value of potential (at $»-0.7 \mathrm{~V}$ ). This peak is thought to correspond to a single electrochemical 
step, which may be the oxidation of $\mathrm{Ni}$ to $\mathrm{Ni}(\mathrm{OH})_{2}$ according to the reaction:

$$
\mathrm{Ni}+2 \mathrm{H}_{2} \mathrm{O} \rightarrow \mathrm{Ni}(\mathrm{OH})_{2}+2 \mathrm{H}^{+}+2 \mathrm{e}^{-}
$$

The equilibrium potential of this reaction according to Pourbaix ${ }^{17}$ was found to be:

$E_{\mathrm{p}}=0.11-0.0591 \mathrm{pH}$

Giving a redox potential of $-0.7 \mathrm{~V}$ (SCE) in $0.1 \mathrm{M} \mathrm{NaOH}$ solution, is in a good agreement with the experimentally reported values for peak $(A)$.

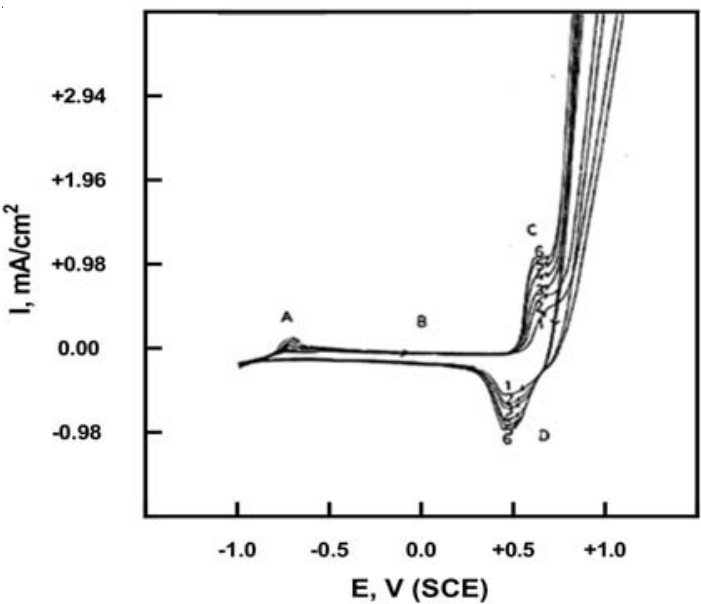

Fig.1. Cyclic voltammetry of $\mathrm{Ni}$ in different concentrations of $\mathrm{NaOH}$ solution at $25 \mathrm{mV} / \mathrm{sec}$.

(1) $0.05 \mathrm{M} \mathrm{NaOH}$ (2) $0.10 \mathrm{M} \mathrm{NaOH}$ (3) $0.15 \mathrm{M} \mathrm{NaOH}$

(4) $0.20 \mathrm{M} \mathrm{NaOH}$ (5) $0.25 \mathrm{M} \mathrm{NaOH}$ (6) $0.30 \mathrm{M} \mathrm{NaOH}$

However, there is a sufficient evidence concerning the formation of $\mathrm{Ni}(\mathrm{OH})_{2}$ in alkaline solutions ${ }^{18}$ in the potential range corresponding to the anodic current of peak (A). From consideration of the charge amounts under peak $(A)$, several investigators ${ }^{19,20}$ gave good evidence for the formation of only a mono-layer of $\mathrm{Ni}(\mathrm{OH})_{2}$ on the electrode surface. It has been reported by Schrebler et al., ${ }^{21}$ that $\mathrm{Ni}(\mathrm{OH})_{2}$ appears as hydrated species on the metal surface, once its solubility product is exceeded. Furthermore, in aqueous solutions $\mathrm{Ni}(\mathrm{OH})_{2}$ is bound to a well known equilibrium in solution

$$
\begin{aligned}
& \mathrm{Ni}(\mathrm{OH})_{2}=\mathrm{Ni}(\mathrm{OH})^{+}+\mathrm{OH}^{-} \\
& \mathrm{Ni}(\mathrm{OH})^{+}=\mathrm{Ni}^{2+}+\mathrm{OH}^{-} \\
& \text {and/or } \mathrm{Ni}(\mathrm{OH})_{2}=\mathrm{HNiO}^{-}+\mathrm{H}^{+}
\end{aligned}
$$

The latter species are particularly important in alkaline solutions since it entails the anodic dissolution of nickel as a complex anion.

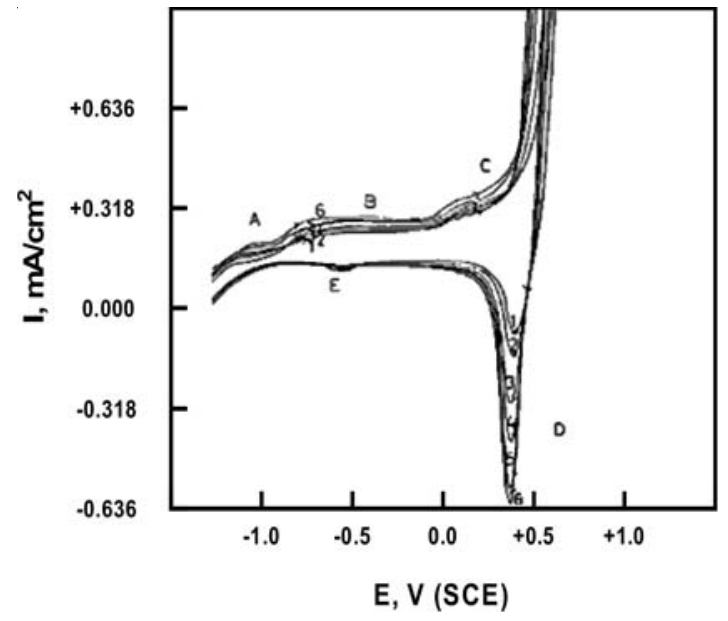

Fig. 2. Cyclic voltammetry of Inconel 600 in different concentrations of $\mathrm{NaOH}$ solution at 25 $\mathrm{mV} / \mathrm{sec}$. (1) $0.05 \mathrm{M} \mathrm{NaOH}$ (2) $0.10 \mathrm{M} \mathrm{NaOH}$ (3) $0.15 \mathrm{M} \mathrm{NaOH}$ (4) $0.20 \mathrm{M} \mathrm{NaOH}$ (5) $0.25 \mathrm{M} \mathrm{NaOH}$ (6) $0.30 \mathrm{M} \mathrm{NaOH}$

For Incoloy 800 which contains $33.49 \%$ $\mathrm{Ni}$ and $44.95 \% \mathrm{Fe}$, peak $(\mathrm{A})$ may correspond to the oxidation of $\mathrm{Ni}$ and $\mathrm{Fe}$ to $\mathrm{Ni}(\mathrm{OH})_{2}$ and $\mathrm{Fe}(\mathrm{OH})_{2}$ respectively. In case of $316 \mathrm{SS}$ (of high iron content) this peak appears at $\approx-0.6 \mathrm{~V}$ (S.C.E.), it may correspond to the formation of $\mathrm{Fe}(\mathrm{OH})_{2}$ according to the reaction :

$\mathrm{Fe}+2 \mathrm{H}_{2} \mathrm{O} \rightarrow \mathrm{Fe}(\mathrm{OH})_{2}+2 \mathrm{H}^{+}+2 \mathrm{e}^{-}$

After peak $(A)$, there is a passive region (region $\mathrm{B}$ ). The current flowing along this region is commonly identified as the corrosion current which is used to counteract the chemical dissolution of the passive film. The alkali concentration has no significant effect on the current flowing along region (B) of the CV in the case of nickel as shown in Fig. 1, The current remains constant along a wide potential range amoun-ting to about $1 \mathrm{~V}$ due to the stability of the passivating oxide film. Along this potential region, the passivation current is totally used in repairing the oxide film attacked chemically by the alkali.

Davis and Barker ${ }^{22}$ suggested that, the quantity of electricity passed through this region is used in the formation of $\mathrm{Ni}(\mathrm{OH})_{2}$, which fills in any pores existing in the already formed film, the remainder causes a certain amount of the film growth. In case of $\mathrm{Ni}$ and Inconel 600, this region may involve the formation of $\mathrm{NiO}$, either by an irreversible chemical reaction:

$\mathrm{Ni}(\mathrm{OH})_{2} \rightarrow \mathrm{NiO}+\mathrm{H}_{2} \mathrm{O}$ 
or electrochemical reaction :

$\mathrm{Ni}(\mathrm{OH})_{2} \rightarrow \mathrm{NiO}+2 \mathrm{H}^{+}+2 \mathrm{e}$

X-rays photoelectron spectroscopy (XPS) ${ }^{23}$ indicates that the film formed on the $\mathrm{Ni}$ electrode surface is probably composed of $\mathrm{NiO}$ and $\mathrm{Ni}(\mathrm{OH})_{2}$, the former being the passivating species. The present results are mostly consistent with the spectroscopic conclusions and with the results of Schrebler et al., ${ }^{21}$.

The major constituent of the passive film formed on the alloys containing certain amounts of chromium is hydrated chromium oxyhydroxide $\mathrm{CrO}_{x}(\mathrm{OH})_{3-2 x} \mathrm{nH}_{2} \mathrm{O}^{24}$, where $\mathrm{n}$ dependent upon the composition and quality of the underlying alloy and the condition of film formation.

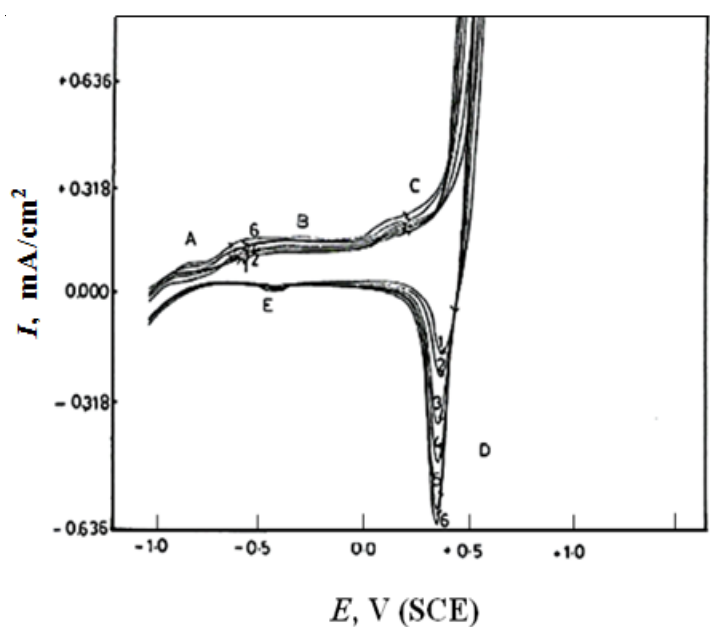

Fig.3. Cyclic voltammetry of Incoloy 800 in different concentrations of $\mathrm{NaOH}$ solution at 25 mV/sec. (1) $0.05 \mathrm{M} \mathrm{NaOH}$ (2) $0.10 \mathrm{M} \mathrm{NaOH}$ (3) $0.15 \mathrm{M} \mathrm{NaOH}$ (4) $0.20 \mathrm{M} \mathrm{NaOH} \mathrm{(5)} 0.25 \mathrm{M} \mathrm{NaOH}$ (6) $0.30 \mathrm{M} \mathrm{NaOH}$

As the potential of the electrode becomes more positive, another anodic dissolution peak (C) has been observed before the transpassive region which followed by oxygen evolution. This peak may be attributed to the oxidation $\mathrm{Ni}(\mathrm{OH})_{2}$ or $\mathrm{NiO}$ formed at the peak (A) and passive region (B) to some higher oxides of nickel. The oxidation of $\mathrm{Ni}(\mathrm{OH})_{2}$ to a higher nickel oxide ${ }^{25}$. There-fore, in case of $\mathrm{Ni}$ and Inconel 600 , this peak can also be related to the oxidation of $\mathrm{Ni}(\mathrm{OH})_{2}$ to $\mathrm{NiOOH}$ according to :

$\mathrm{Ni}(\mathrm{OH})_{2} \rightarrow \mathrm{NiOOH}+\mathrm{H}^{+}+\mathrm{e}^{-}$

Hashimoto and Asami ${ }^{24}$ reported that the passive film formed on Inconel 600 consists of
$\mathrm{Ni}(\mathrm{OH})_{2} \cdot \mathrm{nH}_{2} \mathrm{O}$ which transforms with further increase in the potential to $\mathrm{NiO}(\mathrm{OH})_{2-2 \mathrm{y}} \mathrm{nH}_{2} \mathrm{O}$. In case of Incoloy 800 this peak may be due to the oxidation of $\mathrm{Fe}(\mathrm{OH})_{2}$ and $\mathrm{Ni}(\mathrm{OH})_{2}$ to $\mathrm{FeOOH}$ and $\mathrm{NiOOH}$, whereas for $316 \mathrm{SS}$, peak (C) is related to the oxidation of $\mathrm{Fe}(\mathrm{OH})_{2}$ to $\mathrm{Fe} \mathrm{OOH}$ according to:

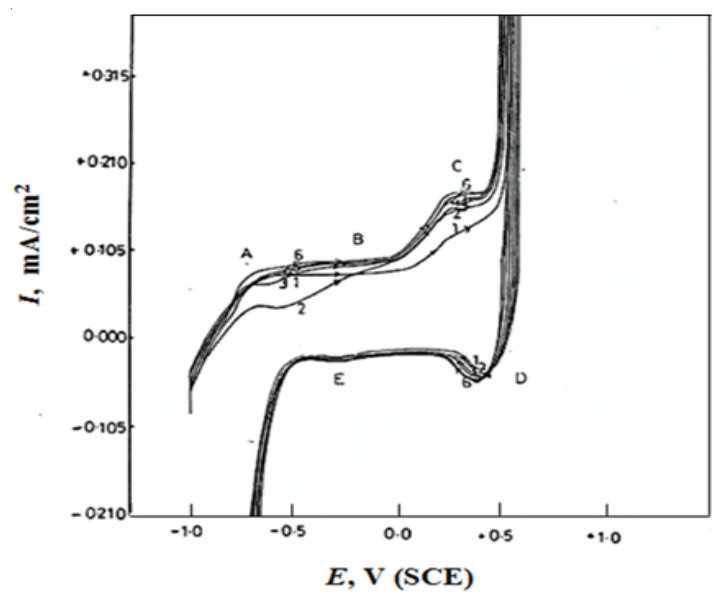

Fig. 4. Cyclic voltammograms of 316 SS in different concentration of $\mathrm{NaOH}$ at $25 \mathrm{mV} / \mathrm{sec}$.
(1) $0.05 \mathrm{M} \mathrm{NaOH}$ (2) $0.10 \mathrm{M} \mathrm{NaOH}$
(3) $0.15 \mathrm{M} \mathrm{NaOH}$
(4) $0.20 \mathrm{M} \mathrm{NaOH}$ (5) $0.25 \mathrm{M} \mathrm{NaOH}$
(6) $0.30 \mathrm{M} \mathrm{NaOH}$

$\mathrm{Fe}(\mathrm{OH})_{2} \rightarrow \mathrm{FeOOH}+\mathrm{H}^{+}+\mathrm{e}^{-}$

When the potential of working electrode is reversed in the cathodic direction after oxygen evolution, there is one cathodic peak (D) appears in the case of nickel as shown in Fig.1. An additional cathodic peak (E) is observed in case of Inconel600, Incoloy800,316 SS (Figs. 2-4).

In case of nickel the cathodic branch of the CV's exhibits no further reduction peaks before the evolution of hydrogen is attained. Thus, some of the reduction products of peak $(D)$ probably nickel oxide or oxyhydroxide remains on the electrode surface down to the hydrogen evolution potential. For Inconel 600 , Incoloy 800 and 316 SS, this peak can be related to the reduction of the oxyhydroxide formed on the anodic branch of the scan. Peak (E) was related to the reduction of the hydroxide remains in the passive region.

\section{Susceptibility of nickel alloys and stainless steel} to pitting corrosion by chloride ions Cyclic voltammetry measurements

The pitting corrosion of nickel alloys and stainless steel, similar to other metals or alloys, 
occurs when the passivity breakdown of local points (anodic sites) on the surface exposed to the corrosive medium, while the major part remains passive. In practice, the pitting may be encountered if the corrosive environments contain chloride, or other aggressive halide ions ${ }^{26-28}$.

The curves of Figs.(5-8) show the cyclic voltammetry of of $\mathrm{Ni}$, Inconel 600 , Incoloy 800 and 316 SS respectively, in $0.1 \mathrm{M} \mathrm{NaOH}$ solution in the absence and presence of increasing concentrations of $\mathrm{NaCl}$ as a pitting corrosion agent at a scanning rate $25 \mathrm{mV} / \mathrm{sec}$.

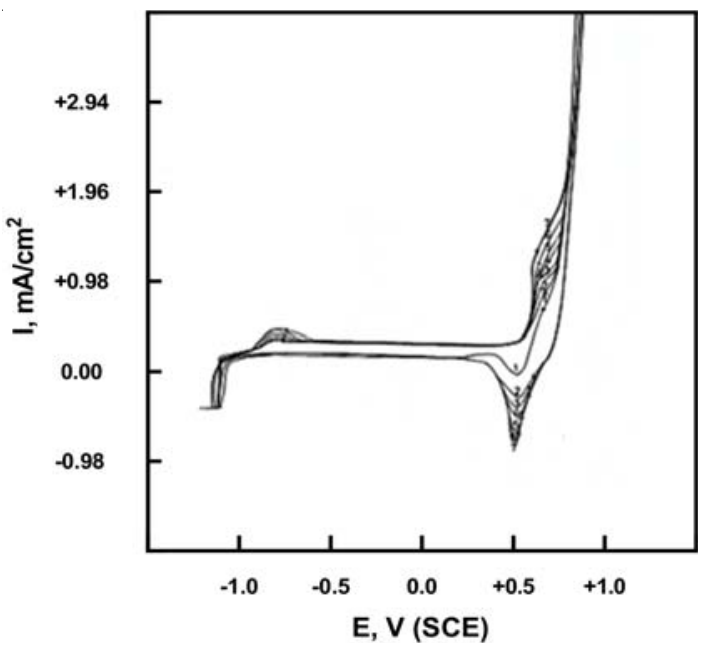

Fig. 5. Cyclic voltammetry of $\mathrm{Ni}$ in $0.1 \mathrm{M} \mathrm{NaOH}$ containing different concentration of $\mathrm{NaCl}$ solution at $25 \mathrm{mV} / \mathrm{sec}$.
(1) $0.00 \mathrm{M} \mathrm{NaCl}$
(2) $1 \times 10^{-2} \mathrm{M} \mathrm{NaCl}$
(3) $3 \times 10^{-2} \mathrm{M} \mathrm{NaCl}$

(4) $5 \times 10^{-2} \mathrm{M} \mathrm{NaCl}$

(5) $7 \times 10^{-2} \mathrm{M} \mathrm{NaCl}$

(6) $1 \times 10^{-1} \mathrm{M} \mathrm{NaCl}$

(7) $1.5 \times 10^{-1} \mathrm{M} \mathrm{NaCl}$

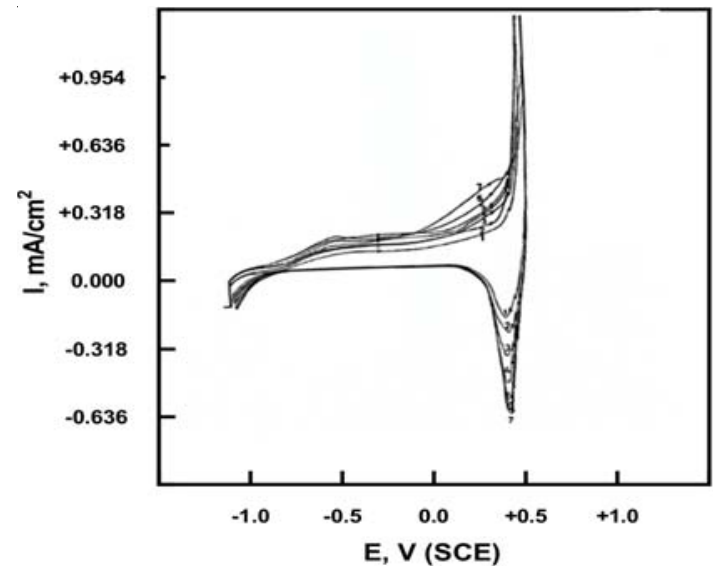

Fig.6. Cyclic voltammetry of Inconel 600 in $0.1 \mathrm{M} \mathrm{NaOH}$ containing different concentration of $\mathrm{NaCl}$ solution (at $25 \mathrm{mV} / \mathrm{sec}$.).
(1) $0.00 \mathrm{M} \mathrm{NaCl}$
(2) $1 \times 10^{-2} \mathrm{M} \mathrm{NaCl}$ (3) $3 \times 10^{-2} \mathrm{M} \mathrm{NaCl}$
(4) $5 \times 10^{-2} \mathrm{M} \mathrm{NaCl}^{\text {(5) }} 7 \times 10^{-2} \mathrm{M} \mathrm{NaCl}$ (6) $1 \times 10^{-1} \mathrm{M} \mathrm{NaCl}$
(7) $1.5 \times 10^{-1} \mathrm{M} \mathrm{NaCl}$

Inspection of the curves of these Fig shows that, the presence of $\mathrm{NaCl}$ up to a certain concentration, which depend on the electrolyte bulk concentration and the type of the electrode, is tolerated by the surface film and has practically no effect on the shape of the CVs reported in chloridefree solution. These halide concentrations are assumed to have no influence on the dissolution kinetics of the passive film on the electrode surface. However, higher concentrations of $\mathrm{Cl}^{-}$ions on the other hand, show a tendency to destroy the passive film formed on the electrode surface. The effect of $\mathrm{Cl}^{-}$ions on the passive film formed on the electrode can be recognized by the marked increase of the flowing currents at potentials, in the passive region, which are more active the higher the concentration of the $\mathrm{Cl}^{-}$ions. This increase in current could be attributed to the destruction of the passive film with the initiation of localized corrosion ${ }^{29-30}$.

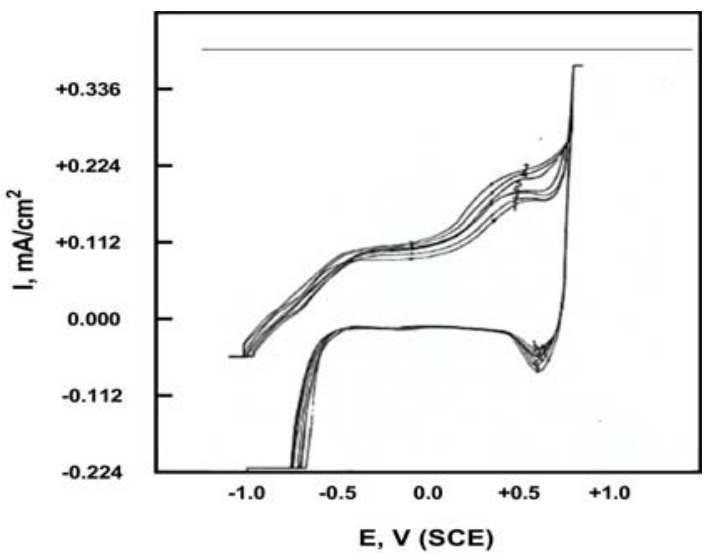

Fig.7. Cyclic voltammetry of Incoloy 800 in $0.1 \mathrm{M}$ $\mathrm{NaOH}$ containing different concentration of $\mathrm{NaCl}$ solution at $25 \mathrm{mV} / \mathrm{sec}$.

$\begin{array}{lll}\text { (1) } 0.00 \mathrm{M} \mathrm{NaCl} & \text { (2) } 1 \times 10^{-2} \mathrm{M} \mathrm{NaCl} & \text { (3) } 3 \times 10^{-2} \mathrm{M} \mathrm{NaCl}\end{array}$

(4) $5 \times 10^{-2} \mathrm{M} \mathrm{NaCl}$ (5) $7 \times 10^{-2} \mathrm{M} \mathrm{NaCl}$ (6) $1 \times 10^{-1} \mathrm{M} \mathrm{NaCl}$

(7) $1.5 \times 10^{-1} \mathrm{M} \mathrm{NaCl}$

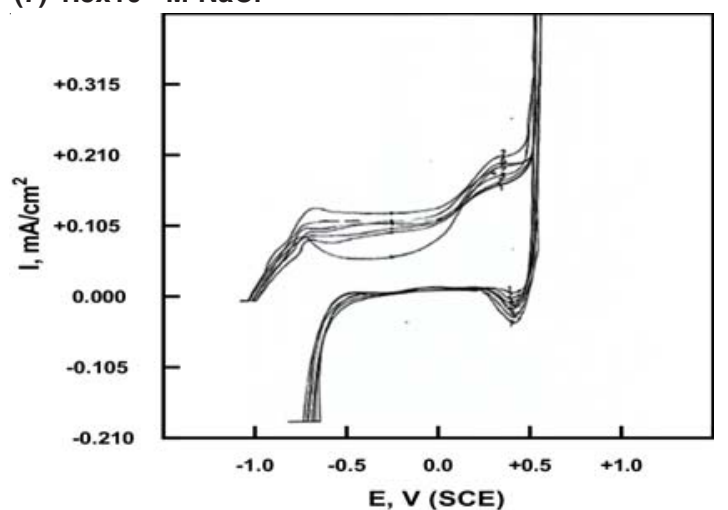

Fig. 8. Cyclic voltammetry of $316 \mathrm{SS}$ in $0.1 \mathrm{M} \mathrm{NaOH}$ containing different concentration of $\mathrm{NaCl}$ solution (at $25 \mathrm{mV} / \mathrm{sec}$.).
(1) $0.00 \mathrm{M} \mathrm{NaCl}$
(2) $1 \times 10^{-2} \mathrm{M} \mathrm{NaCl}$
(3) $3 \times 10^{-2} \mathrm{M} \mathrm{NaCl}$
(4) $5 \times 10^{-2} \mathrm{M} \mathrm{NaCl}$
7) $1.5 \times 10^{-1} \mathrm{M} \mathrm{NaCl}$ 
An interesting feature is observed when the potential of the working electrode is reversed in the cathodic direction. The current starts to decrease gradually with decreasing the electrode potential. Finally the current reaches a zero value, then a large dissolution current peak (areas) formed on the cathodic branch of the CVS. These peaks are enlarged with in-creasing the $\mathrm{Cl}^{-}$ion content of the solution.

The change of the amount of the anodic charge $\mathrm{Dq}_{\mathrm{a}}$ (coulomb. $\mathrm{cm}^{-2}$ ), which is the difference between the anodic charge amounts integrated in the presence and absence of $\mathrm{Cl}^{-}$ion, is taken as a measure of the extent of the pitting corrosion to take place $^{30}$. Fig. 9 represents the variation of $q_{a}$ with the logarithm of the molar concentration of $\mathrm{Cl}$ - ion for $\mathrm{Ni}$, Inconel 600, Incoloy 800 and $316 \mathrm{SS}$. Dq changes only slightly in the presence of low $\mathrm{Cl}^{-}$ion concentrations. This may be attributed to repassivation of the formed pits, while at higher concentrations of the $\mathrm{Cl}^{-}$ion, $\mathrm{Dq}_{a}$ changes markedly and linearly with $\log \mathrm{C}_{\mathrm{C} 1}$ - according to:

$\mathrm{Dq}_{\mathrm{a}}=\mathrm{a}_{1}+\mathrm{b}_{1} \log \mathrm{C}_{\mathrm{C} 1}{ }^{-}$

Where, $a_{1}$ and $b_{1}$ are constants which depend on the solu-tion composition and the scanning rate. Under such conditions of $\mathrm{Cl}^{-}$ion concentrations the formed pits may continuously propagate.

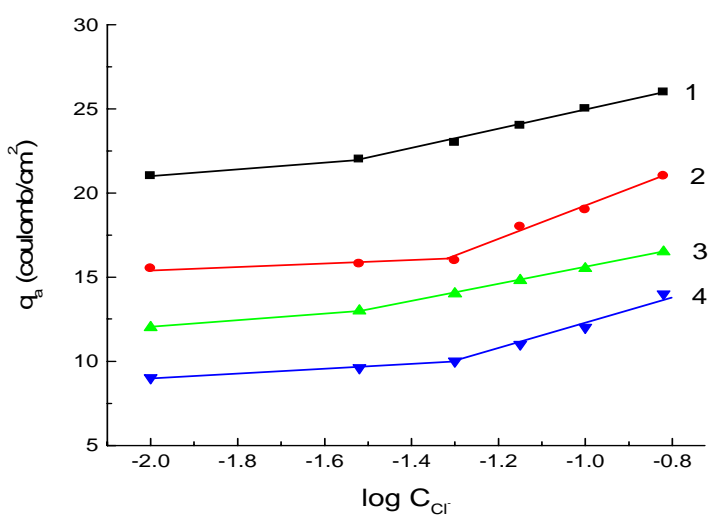

Fig. 9. The relation between the amount of anodic charge $\left(\mathrm{Dq}_{\mathrm{a}}\right)$ and the logarithm of the molar concentration of $\mathrm{Cl}^{-}$ions.(1) $\mathrm{Ni}$ (2) Inconel 600 (3) Incoloy 800 (4) 316 SS

\section{Potentiodynamic anodic polarization}

The curves of Fig.10 represent the potentiodynamic anodic polarization behavior of $\mathrm{Ni}$ in $0.1 \mathrm{M} \mathrm{NaOH}$ solution at a sweep rate of $1.0 \mathrm{mV} /$ sec upon the addition of increasing concentrations of $\mathrm{NaCl}$ as a pitting corrosion agent. Similar curves were obtained for the other alloys namely, Inconel 600 , Incoloy 800 and 316 SS. Inspection of the curves of Fig. 10 reveals that the following aspects:

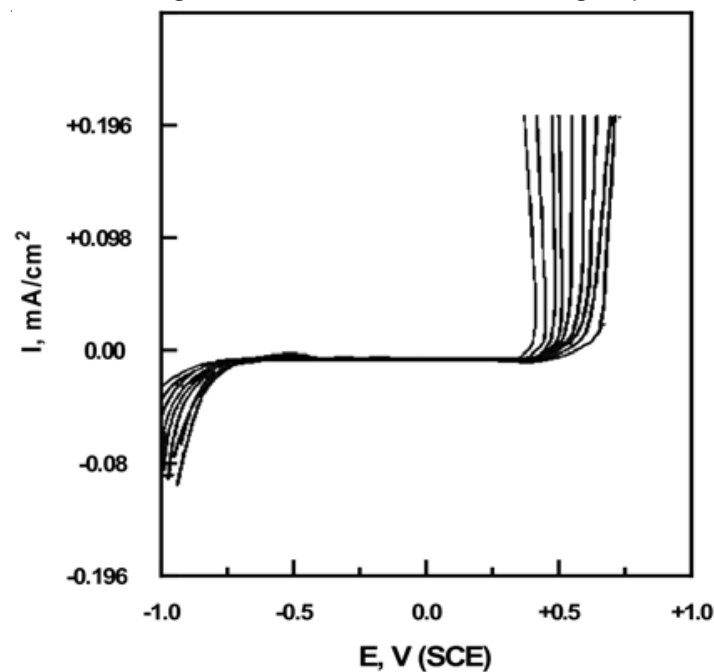

Fig. 10. Potentiodynamic anodic polarization curves of $\mathrm{Ni}$ in $0.1 \mathrm{M} \mathrm{NaOH}$ + different concentrations of $\mathrm{NaCl}$ at $1 \mathrm{mV} / \mathrm{sec}$.

(1) $0.00 \mathrm{M} \mathrm{NaCl}$ (2) $5 \times 10^{-3} \mathrm{M} \mathrm{NaCl}$ (3) $1 \times 10^{-2} \mathrm{M} \mathrm{NaCl}$ (4) $3 \times 10^{-2} \mathrm{M} \mathrm{NaCl}(5) 5 \times 10^{-2} \mathrm{M} \mathrm{NaCl}$ (6) $7 \times 10^{-2} \mathrm{M} \mathrm{NaCl}^{2}(7) 9 \times 10$ ${ }^{2} \mathrm{M} \mathrm{NaCl}(8) 1 \times 10^{-1} \mathrm{M} \mathrm{NaCl}(9) 3 \times 10^{-1} \mathrm{M} \mathrm{NaCl}$

The addition of $\mathrm{Cl}^{-}$ion up to a certain concentration which depends on the $\mathrm{OH}^{-}$ion concentration has practically no effect on the dissolution of the passive film on the metal surface. However, at a certain critical concentration which depends on the alkali concentration, the nature of the metal or alloy, its thermal treatment and the state of its surface. The current flowing along the passive range increases suddenly and markedly at some definite potentials denoting the destruction of the passivating oxide film and the initiation of visible pits. This potential is known the pitting corrosion potential $\left(\mathrm{E}_{\text {pitt }}\right)^{30-31}$

The effect of increasing $\mathrm{Cl}^{-}$ion content of the solution is to shift the pitting potential of the working electrode into active negative direction. Similar findings were reported by Abdallah.et al., ${ }^{30}$ in the case of pitting of pitting corrosion of nickel alloys and stainless steel in chloride solutions

The dependence of pitting corrosion potential of the $\mathrm{Ni}$ electrode, Inconel 600 , Incoloy 800 and 316 SS on the concentrations of the $\mathrm{Cl}^{-}$ion is shown in Fig. 11 which represents the plot of $E_{\text {pitt }}$ 
versus $\log \mathrm{C}_{\mathrm{Cl}}$ in $0.1 \mathrm{M} \mathrm{NaOH}$ solutions. Usually most of the investigations carried out on the pitting corrosion potentials reveals a straight-line relationship between $\mathrm{E}_{\text {pitting }}$ and $\log \mathrm{C}_{\mathrm{Cl}}$ - satisfying the following equation

$E_{\text {pitting }}=\mathrm{a}_{2}-\mathrm{b}_{2} \log \mathrm{C}_{\mathrm{Cl}^{-}}$

Where $a_{1}$ and $b_{1}$ are constants which depend on both the nature and the type of the aggressive anion and the electrode sample.

In case of Incoloy 800 and 316 SS straight line relationship are obtained which fit the relationship according to equation (12). In case of nickel and Inconel 600, the curves are segmoid in nature in which equation (12) is obeyed only within a certain range of $\mathrm{Cl}^{-}$ion concentration. At lower of $\mathrm{Cl}^{-}$ion concentrations the pitting potential shift slightly into negative direction as the concentration of the chloride ions is increased. Therefore, one can conclude that these concentrations of $\mathrm{Cl}^{-}$ions are not sufficient to destroy completely the passivating film on the metal surface, or that pits formed are not completely active and may undergo repassivation ${ }^{32}$.

The pits formed within the concentration range of $\mathrm{Cl}^{-}$ion, where an equation (12) is applicable are assumed to be of the limiting active type which cannot undergo repassivation. However,

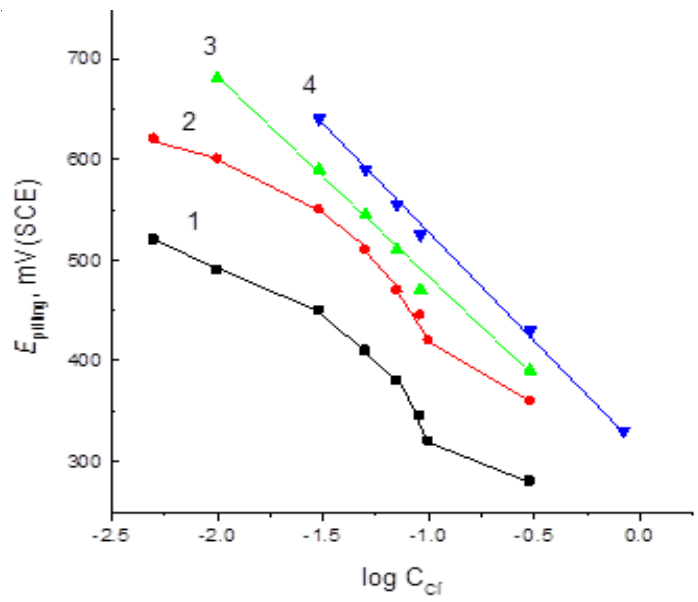

Fig. 11. The relationship between pitting potential and logarithm of molarity of $\mathrm{Cl}^{-}$ions for nickel and the three alloy samples. (1) Ni (2) Inconel 600 (3) Incoloy 800 (4) 316 SS. at higher concentrations of $\mathrm{Cl}^{-}$ions, The pits formed continuously propagated.

Inspection of Fig.11, it is obvious that, at the same concentration of $\mathrm{Cl}^{-}$ion the noble (positive)shift in the potential decreases in the following order: 316 SS > Incoloy $800>$ Inconel $600>\mathrm{Ni}$. This sequence is like the previous work in the case of the effect of $\mathrm{Cl}^{-}$ion on the potentiodynamic anodic polarization curves of nickel alloys and $316 \mathrm{SS}$ in $\mathrm{HNO}_{3}$ solution ${ }^{16}$. It is obvious that the 316 SS is more resistance to pitting attack due to the presence of Mo and $\mathrm{Cr}$ in the chemical composition of 316 SS which improve the thickening of the passive film and consequently increase the resistance of this alloy to pitting corrosion. On the other hand, the Incoloy 800 is more resistance than Inconel 600 due to the higher amount of $\mathrm{Cr}$ content in its chemical composition.

\section{CONCLUSIONS}

1. The cyclic voltammetry technique was constructed of nickel, Inconel 600, Incoloy 800 and 316 SS electrodes in different concentrations of $\mathrm{NaOH}$ solutions.

2. All the curves in the anodic scan characterized by anodic peak $(A)$, passive region $(B)$, anodic dissolution peak $(C)$ before oxygen evolution.

3. In the cathodic scan there is is one reduction peak (D) in case of $\mathrm{Ni}$ electrode but there are two reduction peaks ( $D$ and $E$ )in case of the alloys used.

4. As the concentrations of $\mathrm{Cl}^{-}$ions increase the change of the amount of the anodic charge $\mathrm{Dq}_{a}$ increases and the values of the pitting corrosion potential are shifted to the more negative direction.

5. At one and the same $\mathrm{Cl}^{-}$ion concentration, the resistance to the pitting corrosion decreases in the following order: 316 SS > Inconel $600>$ Incoloy $800>316$ SS.

6. The resistance of the alloys used to pitting corrosion depends on the chemical composition of its. 


\section{REFERENCES}

1. Crum .J.R., Shoemaker L.E, Corrosion resistance of nickel alloys in caustic solutions, Corros., 2006, 3, 12-16.

2. Macdonald. D.P, Cyclic Voltammetry of Copper Metal in Lithium Hydroxide Solution at Elevated Temperatures, J. Electochem. Soc., 1974, 121, 651-656.

3. Kolotyrkin .Y. M., Pitting corrosion of metals, Corrosion,1963, 19 ,261-268.

4. Abdallah .M, Kamar .E. M, El-Etre A. Y, Salah Eid, Gelatin as corrosion inhibitor for aluminum and aluminum silicon alloys in sodium hydroxide solutions Prot. Met. Phys. Chem. surf., 2016 ,52 (1),140-148.

5. Abdallah .M, Al Karane S.O., Abdel Fattah A.A, Inhibition of the corrosion of nickel and its alloys by natural clove oil, Chem. Eng. Comm. 2009,196, 1406-1416

6. Abdallah .M, Al Karane S.O., Abdel Fattah A.A, Inhibition of the corrosion of nickel by natural black cumin oil, Chem. Eng. Comm., 2010,197,1446-1454.

7. Abdallah .M, Zaafarany.I, Khairou.K. S., Emad. Y, Natural Oils as Corrosion Inhibitors for Stainless Steel in Sodium Hydroxide Solutions, Chem Tech. Fuels Oils, 2012, 48 (3), 234-245.

8. Burstein. G. T., Liu C., Souto R. M, Vines S. $\mathrm{P}$,Origins of pitting corrosion, Corrosion Engineering, Science and Technology 2004, 39., 25-30.

9. Abdallah .M, Zaafarany. I, Khairou K. S, Sobhi M., Inhibition of carbon steel corrosion by iron(III) and imidazole in sulfuric acid, Int. J. Electrochem Soc., 2012,7(2),1564-1579.

10. Abdallah.M, Asghar B. H., Zaafarany I., Sobhi M., Synthesis of some aromatic nitro compounds and its applications as inhibitors for corrosion of carbon steel in hydrochloric acid solution Prot. Metals. Phys. Chem . surface, 2013,49(4),485-491.

11. Abdallah .M, El-Etre A.Y., Soliman, M. G , Some organic and inorganic compounds as corrosion inhibitors for dissolution of C-Stee in $3.5 \% \mathrm{NaCl}$ solution. Anti Corros Methods and Materials, 2006, 53 (2),118-123.

12. AL Jahdaly. B. A., Althagafi I. I., Abdallah .M, Khairou K. S., Ahmed. S. A. ,Fluorenone
Hydrazone Derivatives as efficient Inhibitiors of the Acidic and Pitting Corrosion of Carbon Steel. J. Mater. Environ. Sci., $2016,7(5), 1798-1809$.

13. Abdallah .M ,AL Jahdaly. B. A., Al-Malyo $O$. A.,Corrosion Inhibition of Carbon Steel in Hydrochloric Acid Solution using Non- Ionic Surfactants Derived from Phenol Compounds, Int.J. Electrochem Sci., 2015, $10,2740-2754$.

14. Jabir $\mathrm{H}$ Al-Fahemia, Abdallah .M,,Elshafie A. M. Gad, Jahdaly. B. A., Experimental and theoritcal approach studies for melatonin drug as safely corrosion inhibitors for carbon steel using DFT, J. Molecular Liquids, 2016, 222,1157-1163

15. Abdallah .M,Al. Jahdaly. B. A,Salem .M.M, Fawzy.A, Mabrouk E.M., Electrochemical behavior of Nickel Alloys and Stainless Steel in $\mathrm{HNO}_{3}$ using Cyclic Voltammetry Technique. J. Mater. Environ. Sci. 2017, 8(4), 1320-1327.

16. Abdallah .M,Al Jahdaly. B. A,Salem .M.M, Fawzy.A, Abdel Fattah A. A.,Pitting Corrosion of Nickel Alloys and Stainless Steel in Chloride Solutions and its Inhibition Using Some Inorganic Compounds, J. Mater. Environ. Sci. 2017, 8(7),2599-2607.

17. Pourbaix M., Atlas of electrochemical equilibria in aqueous solutions. $2 d$ English ed. Houston, Tex.: National Association of Corrosion Engineers.,1974.

18. MacArthur D. M.,The Hydrated Nickel Hydroxide Electrode Potential Sweep Experiments, J. Electrochem. Soc. 1970, 117, 422-426.

19. Visscher W., Barendrecht .E., The anodic oxidation of nickel in alkaline solution, Electrochim. Acta., 1980, 25, 651-655.

20. Medway S.L.'Lucas C.A,Kowal, A,Nichols R.J,Johnson .D., In situ studies of the oxidation of nickel electrodes in alkaline solution, J. Electroanal. Chem. 2006, 587, 173-181.

21. Schrebler R.S., Vilche J.R., Arvia A.J, The kinetics and mechanism of the nickel electrode-III. The potentiodynamic response of nickel electrodes in alkaline solutions in the potential region of $\mathrm{Ni}(\mathrm{OH})_{2}$ formation, Corros. Sci., 1978, 18, 765-778.

22. Davies D. E. , Barker W. , Influence of $\mathrm{pH}$ on corrosion and passivation of nickel, Corros. 1964, 20, $47-53$. 
23. Grosvenor A.P.,Biesinger M.C.,Smart R C.,Stewart Mclntyre N. , New interpretations of XPS spectra of nickel metal and oxides, Surface Sci, 2006, 600,1771-1779.

24. Hashimoto. H., Asami K., XPS study of surface film on nickel alloys in hot concentrated $\mathrm{NaOH}$, Corros.Sci.,1979,19,427-435.

25. Fu X.Z., Zhu Y.J.,Xu. Q.C.,Li J., Pan J.H.,Xu J.Q., .Lin J.D, Liao D.W. Nickel oxyhydroxides with various oxidation states prepared by chemical oxidation of spherical â- $\mathrm{Ni}(\mathrm{OH})_{2}$, Solid State Ionics, 2007,178, 987-993.

26. Abdallah ,M, Al. Jahdaly. B. A, Sobhi .M., Ali A.I. ,Evaluation of some nonionic surfactants derived from hydroquinol compounds as corrosion inhibitors for Carbon steel in hydrochloric acid, Int.J.Electrochem Sci, 2015, 10(6), 4482-4494.

27. Abd El-Aal E.E., Abd-El Wanees S.M., Galvanostatic study of the breakdown of $\mathrm{Zn}$ passivity by sulphate anions, Corros.Sci., 2003, 51,1780-1788.

28. Abdallah .M, El -Etre A. Y,Mead. A.I., Effect of some nonionic surfactant on the passivity breakdown of $\mathrm{Cu}-\mathrm{Ni}$ alloys in alkaline chloride solution. J. Electrochemical Soc. of India, 1996, 45 (2), 71-78.

29. Abdallah .M, Megahed .H. E., El-Naggar M., Radwan D. Mabrouk,E. M. Pitting corrosion of nickel alloys and its inhibition by some dihydrazide derivatives ,Bull Electrochem., 2003, 19(6), 245-254.

30. Abdallah .M, Abd El-Haleem S.M., Initiation and inhibition of pitting corrosion of Incoloy 800 and 316 Stainless Steel, Bull. Electrochem., 1996, 12 (7-8), 449-458.

31. Abdallah .M, Zaafarany I. A, Abd El Wanees S, Assi R., Breakdown of passivity of nickel electrode in sulphuric acid and its inhibition by pyridnone derivatives using the galvanostatic polarization technique, Int.J.Corro. Scale Inib., 2015,4(4) ,338-352

32. Abdallah .M, Mead. A. I,Pitting corrosion of an iron electrode in $\mathrm{HCO}^{-} 3 / \mathrm{Cl}^{-}$solutions and its inhibition by some nonionic surfactants, Annali Di Chimica: 1993, 83, 4,24-430. 